\title{
Management of anticoagulants and antiplatelet agents in elective endoscopy: Weighing the risks and benefits
}

\author{
Paul J Belletrutti MD FRCPC, Steven J Heitman MSc MD FRCPC
}

\begin{abstract}
A encountered in gastroenterology practice. The management of these patients at the time of elective endoscopy can be challenging. Furthermore, this population has not been well studied, and thus, current guidelines are largely based on expert opinion. Ultimately, the risk of bleeding must be weighed against the risk of thromboembolic events when deciding whether to reverse anticoagulation or discontinue antiplatelet therapy before endoscopy. The present paper discusses three scenarios to highlight the authors' own clinical practice, and reviews the current published guidelines on this topic.
\end{abstract} $s$ the indications for endoscopic diagnosis and therapy continue to expand, an increasing number of patients receiving anticoagulants and antiplatelet agents will be

\section{CASES TO CONSIDER}

\section{Case 1}

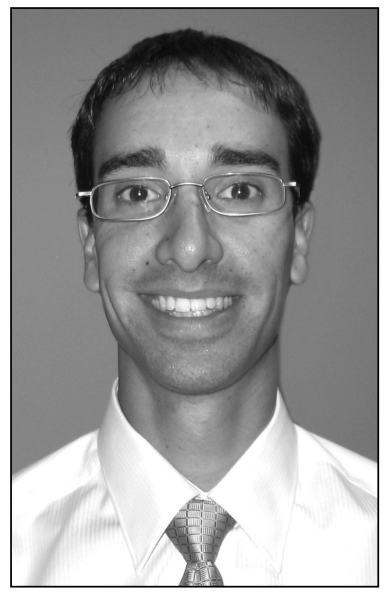

Dr Paul J Belletrutti

been on long-term acetylsalicylic acid (ASA) and clopidogrel since she suffered a transient ischemic attack while on ASA two years ago. You anticipate performing a dilation.

A 58-year-old man is scheduled for a screening colonoscopy. He is asymptomatic, but his brother had colonic polyps and his father was diagnosed with colon cancer at 60 years of age. The patient has essential hypertension and is on lifelong warfarin therapy for chronic atrial fibrillation. He has no history of thromboembolic events.

\section{Case 2}

A 41-year-old woman has abdominal pain and elevated liver enzymes. A transabdominal ultrasound reveals cholelithiasis and a dilated biliary tree, but no obvious choledocholithiasis. She is on lifelong warfarin therapy for a mechanical mitral valve. You are planning to perform an endoscopic retrograde cholangiopancreatography plus sphincterotomy for her suspected common bile duct stone(s).

\section{Case 3}

A 52-year-old woman is referred for an upper endoscopy due to recurrent solid food dysphagia. She has a history of a peptic stricture and was dilated five years ago. She is diabetic and has

\section{PROCEDURE-RELATED BLEEDING RISKS}

The potential to cause significant or uncontrolled bleeding varies, depending on the endoscopic procedure performed. Clinically significant bleeding has been defined as bleeding that requires hospitalization, transfusion, endoscopic intervention and/or surgery (1-3). In the absence of anticoagulants and antiplatelet agents, the American Society for Gastrointestinal Endoscopy (ASGE) has defined a low-risk procedure as one that carries a risk of clinically significant bleeding of less than $1 \%(1)$. This includes diagnostic upper and lower endoscopies, endoscopic retrograde cholangiopancreatography without sphincterotomy and endoscopic ultrasound without fineneedle aspiration (Table 1). High-risk procedures carry greater than $1 \%$ risk of clinically significant bleeding, such as colonic polypectomy (range $0.2 \%$ to $3 \%$ risk) $(4,5)$, variceal band ligation (range $3 \%$ to $5 \%$ risk) $(6,7)$ and endoscopic sphincterotomy (range $0.76 \%$ to $3.2 \%$ risk) $(8,9)$. Also included in this group are interventions that have the potential to produce bleeding that is inaccessible or uncontrollable by endoscopic means, such as endoscopic ultrasound-guided fine-needle aspiration, pneumatic balloon dilation and percutaneous endoscopic gastrostomy tube placement (Table 1).

\section{CONDITION-RELATED THROMBOEMBOLIC RISKS}

Similarly, the indications for which anticoagulants are prescribed can be stratified into low- and high-risk thromboembolic conditions, based on the annual risk of stroke or risk of recurrent venous thromboembolism (Table 1) $(10,11)$. For example, considering all patients with nonvalvular atrial fibrillation, the annual stroke rate without anticoagulation is $4 \%$ to $5 \%(11)$. 
TABLE 1

Procedure and condition risks during elective endoscopy

\section{Procedure risks}

\begin{tabular}{ll}
\hline High-risk & Low-risk \\
$\begin{array}{l}\text { Variceal band ligation } \\
\text { Biliary sphincterotomy }\end{array}$ & EGD \pm biopsy \\
Gastric polypectomy & Colonoscopy \pm biopsy \\
Colonic polypectomy & Diagnostic ERCP \pm stent insertion \\
EUS with FNA & Diagnostic EUS \\
PEG tube placement & \\
$\begin{array}{l}\text { Esophageal dilation } \\
\text { Condition risks }\end{array}$ & \\
\hline $\begin{array}{l}\text { High-risk } \\
\text { Atrial fibrillation with }>1 \text { clinical } \\
\text { risk factor or prosthetic valve }\end{array}$ & Nonvalvular atrial fibrillation with \\
Within three months of DVT & More than three months after DVT \\
Mechanical valve in mitral & New-generation mechanical valve \\
position, or in mitral and aortic & in aortic position \\
position; or old generation & \\
ball-cage valve & \\
Previous cardiac embolism & \\
\hline
\end{tabular}

$\overline{D V T}$ Deep vein thrombosis; EGD Esophagogastroduodenoscopy; ERCP Endoscopic retrograde cholangiopancreatography; EUS Endoscopic ultrasound; FNA Fine-needle aspiration; PEG Percutaneous endoscopic gastrostomy

However, a patient with atrial fibrillation and no other high-risk conditions (ie, congestive heart failure, hypertension, diabetes, age older than 75 years or previous stroke) has an adjusted annual stroke risk of $1.9 \%$ (low-risk condition). In contrast, an individual with all five risk factors has an annual stroke risk of 18.5\% (high-risk condition) (12). Twenty per cent of strokes are fatal, and $40 \%$ result in permanent disability (13). Overall, anticoagulation lowers the risk of arterial or venous thromboembolism by $66 \%$ to $80 \%(10,13)$. Therefore, the decision to reverse anticoagulation therapy is not always straightforward.

\section{WEIGHING THE RISKS}

Based on the above classifications of bleeding and thromboembolic risks, the ASGE has put forth guidelines for the management of warfarin and low molecular weight heparin (LMWH) around the time of endoscopy $(1,14)$. The guidelines state that for low-risk procedures, no adjustment needs to be made to anticoagulation therapy. For high-risk procedures, delaying the procedure should always be considered in cases in which a finite period of anticoagulation has been prescribed. Otherwise, for a high-risk procedure in a patient with a low-risk condition, warfarin should be discontinued three to five days before the procedure. The decision regarding when to restart anticoagulation should be individualized. When both the procedure and the condition are high risk in nature, warfarin should again be discontinued three to five days before the procedure. However, simultaneous bridging anticoagulation therapy with LMWH should be initiated, then held for at least $8 \mathrm{~h}$ before the procedure. Whether to obtain a preprocedure international normalized ratio (INR) and the timing of restarting LMWH and/or warfarin should be individualized based on the nature and success of the intervention. LMWH should be continued until the INR is therapeutic for two to three days, generally three to five days after the procedure (15).
With respect to antiplatelet agents (eg, ASA, nonsteroidal anti-inflammatory drugs and clopidogrel), the available literature (16-18) suggests a theoretically increased risk of bleeding but no difference in clinically significant bleeding when performing any endoscopic procedure, irrespective of the baseline bleeding risk. Thus, the ASGE recommends that, in the absence of a pre-existing bleeding disorder, antiplatelet agents do not need to be discontinued when performing any endoscopic procedure $(1,14)$. However, for high-risk interventions, one can consider discontinuing clopidogrel seven to 10 days before the procedure (14).

\section{Case 1}

\section{CASE ANALYSES}

In this commonly encountered clinical situation, the patient's condition carries a low risk for thromboembolic complications (nonvalvular atrial fibrillation with one risk factor - hypertension). His bleeding risk is either low or high, depending on whether a polypectomy is performed. One strategy would be to perform a diagnostic colonoscopy (low-risk procedure) while the patient is on full anticoagulation and bring the patient back following reversal of anticoagulation for a polypectomy if indicated. Alternatively, his warfarin could be discontinued for three to five days, allowing polypectomy to be performed safely at the time of the initial procedure. In this man's case, the likelihood of encountering polyps is high, given the patient's age and strong family history. We would discontiue his warfarin for five days before colonoscopy and perform a polypectomy during the same procedure if needed. A recent decision analysis supports this strategy as safe and cost effective (19). In addition, we routinely order a preprocedure INR when there is a high likelihood of performing a high-risk procedure. Even if the INR has not completely normalized, one can at least be aware of the factors potentially contributing to bleeding, should it occur. Obtaining an INR is inexpensive, and we see few disadvantages to this approach. Finally, we would instruct the patient to restart warfarin the evening of the procedure in the absence of known complications.

\section{Case 2}

The second case describes a woman with a high-risk condition undergoing a high-risk procedure. A thorough discussion with the patient, outlining both the risks of bleeding and of holding anticoagulation, is critical and should ideally be done in the office setting. She requires discontinuation of warfarin therapy with bridging anticoagulation, using LMWH around the time of her procedure, while her INR is subtherapeutic. LMWH has been shown to be as safe as unfractionated heparin for shortterm thromboprophylaxis of prosthetic valves (20). If available, this is best managed through the expertise of an anticoagulation clinic. We differ from the ASGE guidelines as to when to hold the LMWH before the procedure. The ASGE guidelines state that LMWH should be discontinued at least $8 \mathrm{~h}$ before the procedure, citing that although the duration of action of LMWHs varies, the anticoagulant effect generally does not persist beyond $12 \mathrm{~h}$ (21). There are no published studies on the use of LMWH in the setting of endoscopy, but there is evidence of significant differences between the LMWHs, particularly the duration of action (22). Our approach takes into account this variable therapeutic effect: $\mathrm{LMWH}$ are held either $12 \mathrm{~h}$ or $24 \mathrm{~h}$ before the procedure, depending on whether it is dosed every $12 \mathrm{~h}$ or $24 \mathrm{~h}$, respectively. 
We prefer to schedule these procedures earlier in the day to minimize the risk of patients presenting with early bleeding complications in the middle of the night. Given that endoscopic sphincterotomy carries one of the highest bleeding risks, our policy is to check the patient's INR the morning of the procedure. We either delay the case or administer fresh frozen plasma if the INR is greater than 1.5. In this case, LMWH and warfarin should be restarted expediently. However, we prefer to wait at least $24 \mathrm{~h}$ after the procedure to restart anticoagulation, to minimize bleeding while respecting the higher risk of thrombosis.

\section{Case 3}

The third case describes a woman with a low-risk condition who is undergoing a high-risk procedure. Following the ASGE recommendations, one could continue the ASA and consider holding the clopidogrel, given the high likelihood of performing a dilation. There is a theoretical risk of prolonged bleeding with antiplatelet agents and a lack of evidence for equivocal

\section{REFERENCES}

1. Eisen GM, Baron TH, Dominitz JA, et al. Guideline on the management of anticoagulation and antiplatelet therapy for endoscopic procedures. Gastrointest Endosc 2002;55:775-9.

2. Cotton PB, Lehman G, Vennes J, et al. Endoscopic sphincterotomy complications and their management: An attempt at consensus. Gastrointest Endosc 1991;37:383-93.

3. Gibbs DH, Opelka FG, Beck DE, Hicks TC, Timmcke AE, Gathright JB Jr. Postpolypectomy colonic hemorrhage. Dis Colon Rectum 1996;39:806-10.

4. Nelson DB, McQuaid KR, Bond JH, Lieberman DA, Weiss DG, Johnston TK. Procedural success and complications of large-scale screening colonoscopy. Gastrointest Endosc 2002;55:307-14.

5. Hui AJ, Wong RM, Ching JY, Hung LC, Chung SC, Sung JJ. Risk of colonoscopic polypectomy bleeding with anticoagulants and antiplatelet agents: Analysis of 1657 cases. Gastrointest Endosc 2004;59:44-8.

6. Sarin SK, Lamba GS, Kumar M, Misra A, Murthy NS. Comparison of endoscopic ligation and propranolol for the primary prevention of variceal bleeding. N Engl J Med 1999;340:988-93.

7. Lo GH, Lai KH, Cheng JS, Lin CK, Hsu PI, Chiang HT. Prophylactic banding ligation of high-risk esophageal varices in patients with cirrhosis: A prospective, randomized trial. J Hepatol 1999;31:451-6.

8. Freeman ML, Nelson DB, Sherman S, et al. Complications of endoscopic biliary sphincterotomy. N Engl J Med 1996;335:909-18.

9. Christensen M, Matzen P, Schulze S, Rosenberg J. Complications of ERCP: A prospective study. Gastrointest Endosc 2004;60:721-31.

10. Optimum duration of anticoagulation for deep-vein thrombosis and pulmonary embolism. Research Committee of the British Thoracic Society. Lancet 1992;340:873-6.

11. European Heart Rhythm Association; Heart Rhythm Society; Fuster V, et al. ACC/AHA/ESC 2006 guidelines for the management of patients with atrial fibrillation - executive summary: A report of the American College of Cardiology/American Heart Association Task Force on Practice Guidelines and the European Society of Cardiology Committee for Practice Guidelines (Writing Committee to Revise the 2001 Guidelines for the Management of Patients With Atrial Fibrillation). J Am Coll Cardiol 2006;48:854-906. bleeding risk in patients on dual antiplatelet therapy. Furthermore, a bleeding complication in this situation would be difficult to control endoscopically. Therefore, our practice is to discontinue both ASA and clopidogrel for seven days before an anticipated therapeutic procedure. We generally restart these medications the day following the procedure.

\section{CONCLUSIONS}

To safely manage patients on anticoagulants and/or antiplatelet agents undergoing elective endoscopy, one must consider both the underlying condition for which anticoagulation has been prescribed and the inherent bleeding risk of the scheduled procedure. Although guidelines are available, each clinical scenario demands a careful and individualized approach, including a thorough discussion of the risks and benefits with the patient. In this increasingly common and relatively understudied population, we believe that it is always best to "err on the side of caution'.
12. Gage BF, Waterman AD, Shannon W, Boechler M, Rich MW, Radford MJ. Validation of clinical classification schemes for predicting stroke: Results from the National Registry of Atrial Fibrillation. JAMA 2001;285:2864-70.

13. Risk factors for stroke and efficacy of antithrombotic therapy in atrial fibrillation. Analysis of pooled data from five randomized controlled trials. Arch Intern Med 1994;154:1449-57. (Erratum in 1994;154:2254).

14. Zuckerman MJ, Hirota WK, Adler DG, et al. ASGE guideline: The management of low-molecular-weight heparin and nonaspirin antiplatelet agents for endoscopic procedures. Gastrointest Endosc 2005;61:189-94.

15. White RH, McKittrick T, Hutchinson R, Twitchell J. Temporary discontinuation of warfarin therapy: Changes in the international normalized ratio. Ann Intern Med 1995;122:40-2.

16. Komatsu T, Tamai Y, Takami H, Yamagata K, Fukuda S, Munakata A. Study for determination of the optimal cessation period of therapy with anti-platelet agents prior to invasive endoscopic procedures. J Gastroenterol 2005;40:698-707.

17. Shiffman ML, Farrel MT, Yee YS. Risk of bleeding after endoscopic biopsy or polypectomy in patients taking aspirin or other NSAIDS Gastrointest Endosc 1994;40:458-62.

18. Hussain N, Alsulaiman R, Burtin P, et al. The safety of endoscopic sphincterotomy in patients receiving antiplatelet agents: A casecontrol study. Aliment Pharmacol Ther 2007;25:579-84.

19. Gerson LB, Triadafilopoulos G, Gage BF. The management of anticoagulants in the periendoscopic period for patients with atrial fibrillation: A decision analysis. Am J Med 2004;116:451-9.

20. Shapira Y, Sagie A, Battler A. Low-molecular-weight heparin for the treatment of patients with mechanical heart valves. Clin Cardiol 2002;25:323-7.

21. Hirsh J, Warkentin TE, Shaughnessy SG, et al. Heparin and lowmolecular-weight heparin: Mechanisms of action, pharmacokinetics, dosing, monitoring, efficacy, and safety. Chest 2001;119(1 Suppl):64S-94S.

22. Fareed J, Hoppensteadt D, Schultz C, et al. Biochemical and pharmacologic heterogeneity in low molecular weight heparins. Impact on the therapeutic profile. Curr Pharm Des 2004;10:983-99. 


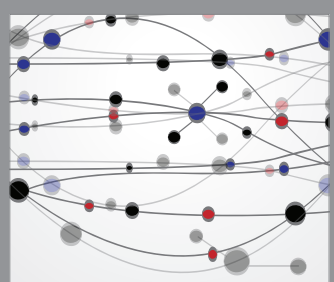

The Scientific World Journal
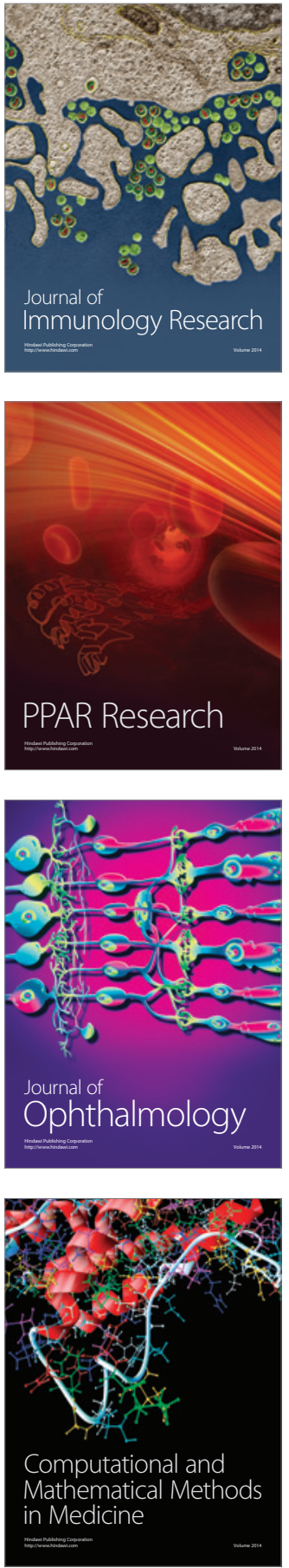

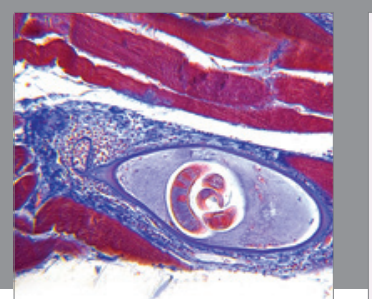

Gastroenterology Research and Practice

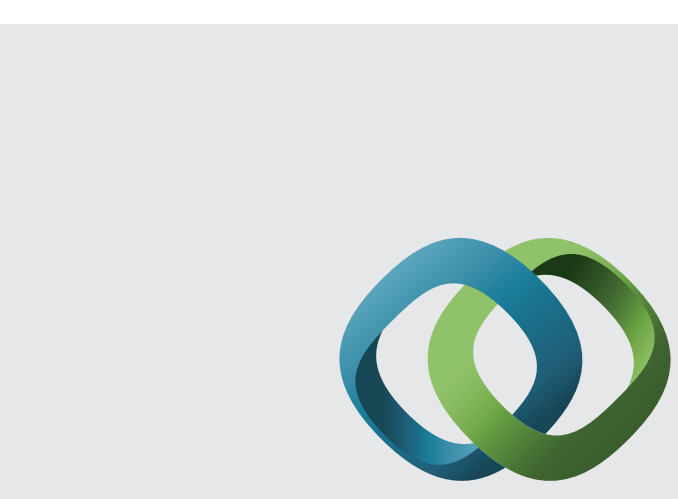

\section{Hindawi}

Submit your manuscripts at

http://www.hindawi.com
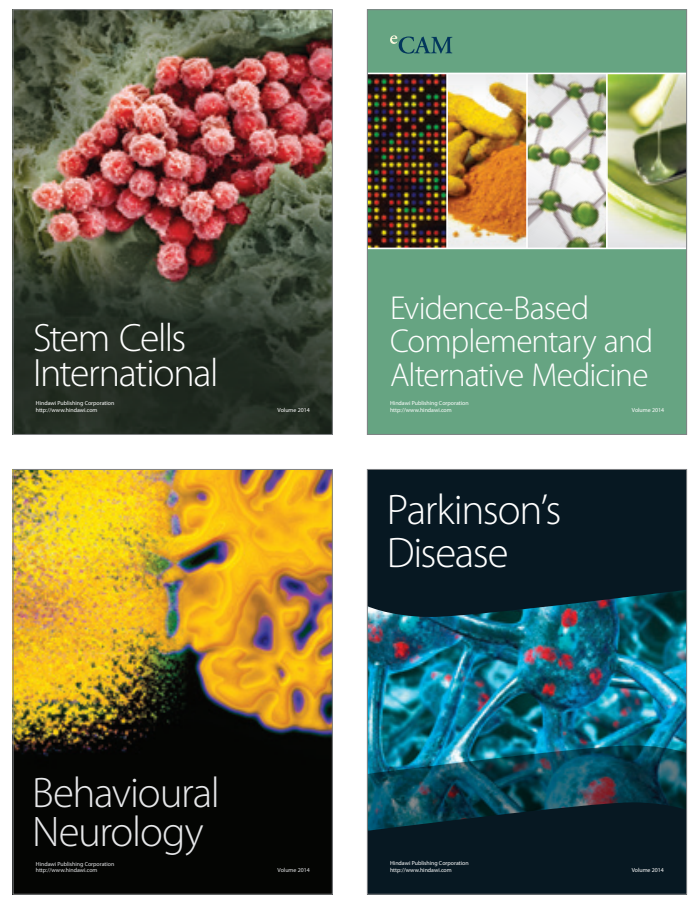
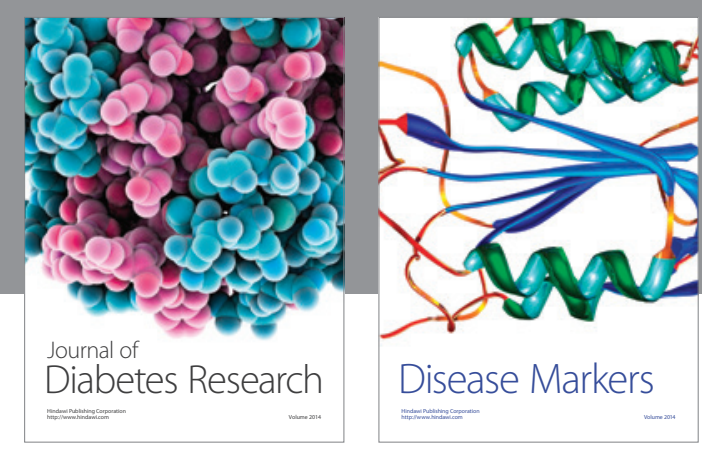

Disease Markers
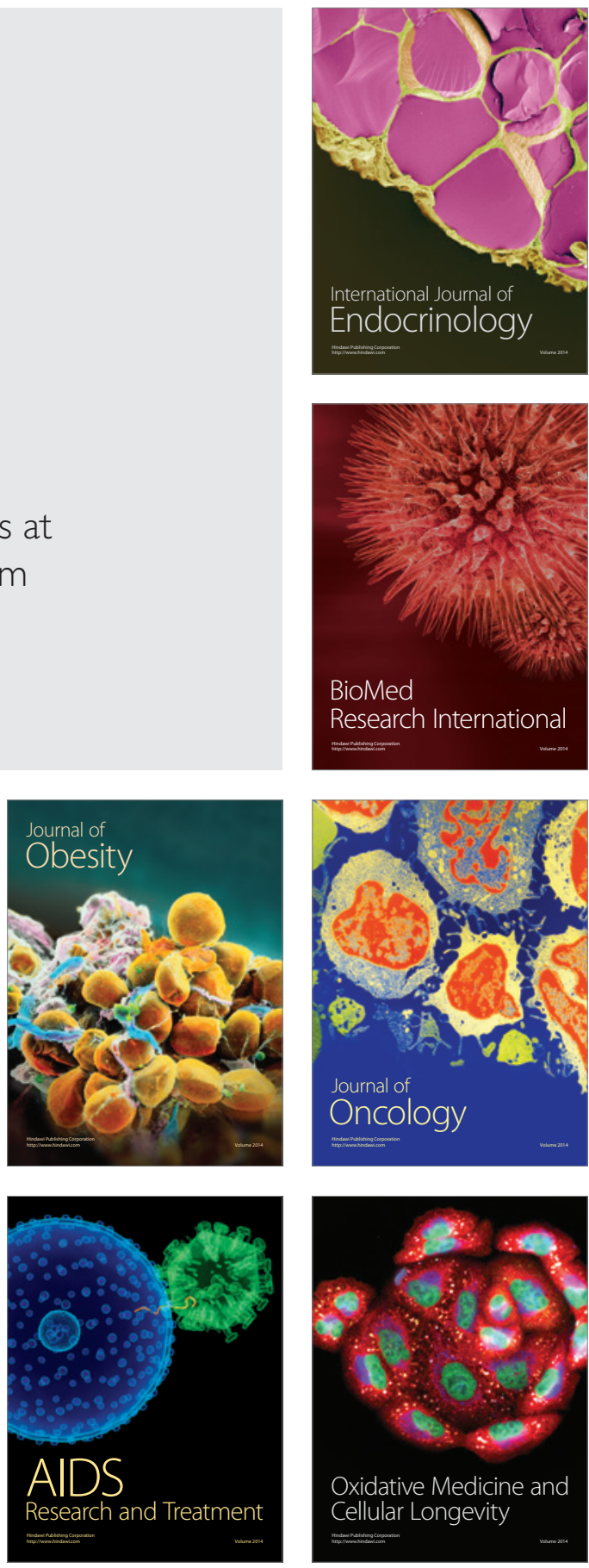